\title{
The optic disc in glaucoma, III: diffuse optic disc pallor with raised intraocular pressure
}

\author{
R. A. HITCHINGS \\ From the Institute of Ophthalmology, Moorfields Eye Hospital, London
}

SUMMARY Ten patients (14 eyes) with chronic simple glaucoma are described, each with features atypical for this disease and more suggestive that each had suffered an acute ischaemic optic neuropathy. Diagnosis of an acute ischaemic optic neuropathy in these cases is important, as treatment of ocular hypertension in the contralateral 'normal' eye may prevent a similar attack.

Optic nerve disease and visual loss in chronic simple glaucoma probably occur as a result of several different mechanisms. Sudden field loss following an acute ischaemic optic neuropathy may be only one of them.

A close relationship between the appearance of the optic disc in glaucomatous eyes and the presence or absence of visual field loss has been emphasised in recent years (Armaly, 1969; Douglas et al., 1974; Hoskins and Gelber, 1975; Hitchings and Spaeth, 1977). Visual field defects of a nerve fibre bundle type have been found to coexist with changes at the neuroretinal rim at the site of the nerve fibres presumed to be involved. Hitchings and Spaeth (1977) divided these changes at the affected part of the neuroretinal rim into thinning or absence of the rim with or without obvious pallor. The decrease in the width of the rim was associated with an increase in the vertical cup/disc ratio, and if not associated with 'pallor' might or might not have had an associated field defect. 'Pallor' of the neuroretinal rim was found in conjunction with visual field defects and would be localised to the area of the rim considered to correspond with the defect in the visual field. Hitchings and Spaeth (1977) found these signs adequate to identify field loss correctly in over $80 \%$ of eyes with glaucoma. Few eyes in the remaining $20 \%$ did not, in retrospect, show localised changes at the neuroretinal rim.

This paper reports on 10 patients (14 eyes), each with an intraocular pressure greater than $21 \mathrm{mmHg}$ and glaucomatous cupping, most with 'nerve fibre bundle' field defects, in which the optic disc did not show the expected localised changes. It is suggested that each of these eyes had suffered an acute ischaemic optic neuropathy, and, although by definition each eye had chronic simple glaucoma, the process

Address for reprints: Mr R. A. Hitchings, FRCS, King's College Hospital, Denmark Hill, London SE5 9RS by which visual loss occurred may well differ from that occurring in 'typical' chronic simple glaucoma showing localising signs at the optic disc.

\section{Materials and methods}

The 10 patients, aged 50 to 80 years, mean $66 \cdot 5$ years, were referred for evaluation of their glaucoma. Each had been discovered to have 'glaucomatous cupping', intraocular pressures greater than 21 $\mathrm{mmHg}$ at the time of referral to the author, and, in 11 of the 14 eyes, glaucomatous visual field defects. Each was subjected to a full ophthalmic examination. Each eye had an open angle on gonioscopic examination. Visual field examinations were performed with a Goldmann perimeter. In each case this visual field examination was supplemented by specific confrontation field testing to look for a central scotoma by means of simultaneous presentation of 2 identical red-coloured targets, 1 each to central and paracentral fields. Mydriasis and slitlamp biomicroscopy of the posterior segment were performed in each case. Evaluation of the optic disc and retinal nerve fibres followed the method described by Hitchings and Spaeth (1976).

The colour of the neuroretinal rim of each optic disc was noted to be either pink or pale. Colour estimation was made by examining the disc with a slit beam of light and then comparing the appearance of one sector of the rim (say, inferotemporal) with other sectors of the same optic disc as well as the corresponding sector of the contralateral optic disc. By this means diffuse (uniform) pallor or localised pallor of the neuroretinal rim could be appreciated. 
Table 1 Summary of results

\begin{tabular}{|c|c|c|c|c|c|c|c|c|c|c|}
\hline $\begin{array}{l}\text { Patient } \\
\text { number }\end{array}$ & $\begin{array}{l}\text { Age at } \\
\text { presentation }\end{array}$ & $\begin{array}{l}\text { Presenting } \\
\text { symptoms }\end{array}$ & $\begin{array}{l}\text { Acuity } \\
\text { presen } \\
\text { Right }\end{array}$ & $\begin{array}{l}\text { at } \\
\text { Leftion }\end{array}$ & $\begin{array}{l}\text { Intrao } \\
\text { pressu } \\
\text { presen } \\
\text { Right }\end{array}$ & $\begin{array}{l}\text { cular } \\
\text { re at } \\
\text { tation } \\
\text { Left }\end{array}$ & Optic disc appearance & $\begin{array}{l}\text { Vertic } \\
C / D \\
\text { Right }\end{array}$ & $a l$ & Visual field \\
\hline 1 & 80 & $* \operatorname{LEV} \downarrow \times 6 / 12$ & $6 / 6$ & $6 / 12$ & 26 & 28 & $\begin{array}{l}\mathbf{R} \text { and } \mathbf{L} \text {. Pale disc with } \\
\text { circular cups, retinal } \\
\text { nerve fibres not seen }\end{array}$ & 0.8 & 0.8 & $\begin{array}{l}\text { R. Full } \\
\text { L. Central scotoma and } \\
\text { inferior arcuate defect }\end{array}$ \\
\hline 3 & 77 & $\mathrm{LEV} \downarrow \times 6 / 12$ & $6 / 5$ & $6 / 18$ & 18 & 26 & $\begin{array}{l}\text { R. Pink disc with visible } \\
\text { retinal nerve fibres } \\
\text { L. Pale disc with circular } \\
\text { cup }\end{array}$ & 0.7 & 0.8 & $\begin{array}{l}\text { R. Full } \\
\text { L. Central scotoma }\end{array}$ \\
\hline 4 & 61 & $\mathrm{REV} \downarrow \times 12 / 12$ & $6 / 9$ & $6 / 6+$ & 45 & 40 & $\begin{array}{l}\mathbf{R} \text { and } \mathbf{L} \text {. Pale disc with } \\
\text { circular cups. Retinal } \\
\text { nerve fibres not seen }\end{array}$ & 0.7 & 0.6 & $\begin{array}{l}\text { R. Central scotoma with } \\
\text { inferior altitudinal field } \\
\text { loss } \\
\text { L. Inferior altitudinal field } \\
\text { loss }\end{array}$ \\
\hline 5 & 60 & $\begin{array}{l}\text { LE } \\
\text { Pain } \times 3 / 32\end{array}$ & $6 / 9$ & $6 / 18$ & 21 & 24 & $\begin{array}{l}\text { R. Pink disc with circular } \\
\text { cup and visible nerve } \\
\text { fibres } \\
\text { L. Pale disc with circular } \\
\text { cup, retinal nerve fibres } \\
\text { not seen }\end{array}$ & $0 \cdot 3$ & 0.5 & $\begin{array}{l}\text { R. Full field } \\
\text { L. Central scotoma with } \\
\text { upper arcuate defect }\end{array}$ \\
\hline 6 & 66 & REV $\downarrow \times 6 / 12$ & $6 / 12$ & $6 / 6$ & 56 & 40 & $\begin{array}{l}\text { R. Pale disc with circular } \\
\text { cup } \\
\text { L. Pale disc with vertically } \\
\text { oval cup. Retinal nerve } \\
\text { fibres not seen }\end{array}$ & 0.8 & 0.8 & $\begin{array}{l}\text { R. Central scotoma } \\
\text { L. Paracentral scotoma in } \\
\text { upper field }\end{array}$ \\
\hline 7 & 65 & $\mathrm{LEV} \downarrow \times 3 / 12$ & $6 / 6$ & $6 / 9$ & 18 & 40 & $\begin{array}{l}\text { R. Pink disc, visible retinal } \\
\text { nerve fibres } \\
\text { L. Pale disc with circular } \\
\text { cup, retinal nerve fibres } \\
\text { not seen }\end{array}$ & 0.4 & 0.8 & $\begin{array}{l}\text { R. Full field } \\
\text { L. Inferior arcuate defect }\end{array}$ \\
\hline 8 & 72 & $\mathrm{LEV} \downarrow \times 2 / 12$ & $6 / 6$ & $6 / 9$ & 20 & 30 & $\begin{array}{l}\text { R. Pink disc, visible retinal } \\
\text { nerve fibres } \\
\text { L. Pale disc with circular } \\
\text { cup, retinal nerve fibres } \\
\text { not seen }\end{array}$ & 0.1 & 0.5 & $\begin{array}{l}\text { R. Full field } \\
\text { L. Inferior altitudinal } \\
\text { defect }\end{array}$ \\
\hline 9 & 50 & $\begin{array}{l}\text { Amaurosis } \\
\text { fugax } \\
\mathbf{R} \text { eye }\end{array}$ & $6 / 9$ & $6 / 9$ & 14 & $14+$ & $\begin{array}{l}\text { R. Disc pale, retinal nerve } \\
\text { fibres not seen } \\
\text { L. Pink disc with circular } \\
\text { cup and visible retinal } \\
\text { nerve fibres }\end{array}$ & 0.7 & 0.4 & $\begin{array}{l}\text { R. Central scotoma } \\
\text { L. Full field }\end{array}$ \\
\hline 10 & 52 & $\underset{\text { days }}{\mathrm{LEV}} \downarrow \times 6$ & $6 / 9$ & $6 / 18$ & 16 & $16 \dagger$ & $\begin{array}{l}\mathbf{R} \text { and } \mathbf{L} \text {. Pale optic disc } \\
\text { with circular cups. No } \\
\text { retinal nerve fibres seen }\end{array}$ & 0.5 & 0.4 & $\begin{array}{l}\mathbf{R} \text { and } \mathbf{L} . \text { Inferior nasal } \\
\text { defect }\end{array}$ \\
\hline
\end{tabular}

* LEV: Left eye vision. * REV: Right eye vision. † Patients subsequently developed raised intraocular pressure

\section{Results}

The results are summarised in Table 1 . Of the 10 patients 8 presented with (central) visual loss. (In 6 of these patients symptoms had been present for months, and referral to hospital was initiated by the optician on detection of depressed central acuity unaccounted for by refractive errors.) Fourteen of the 20 eyes had diffuse pallor of the optic disc together with a circular orifice of the optic cup.
Five eyes had pink optic discs with small central cups and were considered normal. One eye (the left eye of Patient 7) had a vertically oval cup in an atrophic disc considered typically glaucomatous. No patient had aphakia or marked nuclear sclerosis to alter colour appreciation of the optic disc.

Five patients had bilateral disc pallor. The orifice of the optic cup was circular for all except the left eye of Patient 7. In each case the vertical cup-to-disc ratio was similar in the 2 eyes, not differing by more 
than $0.2 \mathrm{C} / \mathrm{D}$ for any patient. The other 5 patients had 1 optic disc considered normal, the other showing diffuse pallor with a circular orifice to the optic cup (Figs. 1,2). This group of patients exhibited a greater disparity in vertical cup-to-disc ratios between the 2 eyes, the $C / D$ ratio of the normal optic disc being equal to or smaller than the $\mathrm{C} / \mathrm{D}$ ratio of contralateral pale disc (see Table 1).

No retinal nerve fibres could be seen in any of the eyes showing diffuse pallor of the neuroretinal rim, whereas an apparently intact retinal nerve fibre layer could be seen in those eyes with a pink optic disc.

The best corrected visual acuity at presentation to the author was found to be less than $6 / 6$ in at least 1 eye in every patient. This visual defect could not be accounted for by opacities in the optical media. No patient had a manifest squint or gross aneisometropia to suggest amblyopia.

Visual field defects were found only for the eyes with pale optic discs. Eight of these eyes had defects in the lower half of the visual field, while a central scotoma to red was found in 7 eyes. Two eyes had defects in the upper half of the visual field and 1 eye with diffuse pallor of the optic disc had no detectable field defect (see Table 1).

Patient 10 presented to the hospital with a 6-day history of diminished vision in his left eye. Examination of the left eye at that time revealed a swollen optic nerve head; a diagnosis of acute ischaemic optic neuropathy was made (Fig. 3). Raised intraocular pressure was not found until $2 \frac{1}{2}$ years after the initial presentation, at which point the patient was referred to the author. Examination at that time revealed bilateral optic disc pallor with circular cups, having a vertical $C / D$ ratio of 0.5 and 0.4 in the right and left eye (Fig. 4).

\section{Discussion}

The points raised by the cases presented in this paper may be conveniently discussed under three headings. Firstly, the similarities and differences between these cases and 'typical' chronic simple glaucoma. Secondly, the similarities between these cases and 'typical' cases of ischaemic optic neuropathy. Thirdly, the relationship of elevated intraocular pressure to ischaemic optic neuropathy.

SIMILARITIES AND DIFFERENCES BETWEEN THE CASES PRESENTED AND 'TYPICAL'

CHRONIC SIMPLE GLAUCOMA

The optic disc in the normal eye is circular or vertically oval (Tomlinson and Phillips, 1974) while the orifice of the optic cup is circular or horizontally oval (Portnoy, 1973). The retinal nerve fibres may be seen as lines radiating from the disc. The arcuate fibres are most easily seen adjacent to the upper and lower temporal quadrants of the optic disc. Visual field loss in glaucoma is associated with a vertical enlargement of the orifice of the optic cup (Kirsch and Anderson, 1973; Weisman, A. et al., 1973; Portnoy, 1975) following loss of neurones and glia from the neuroretinal rim (Anderson, 1975).

Patients with 'typical' chronic simple glaucoma with visual field loss limited to the upper or lower half show localised thinning of the lower or upper half of the neuroretinal rim. In addition pallor of the same part of the rim and a defect in the adjacent part of the nerve fibre layer are frequently seen (Hitchings and Spaeth, 1977). Patients presented in this paper had visual loss in the upper or lower field, but did not show the expected localised pallor or thinning of the neuroretinal rim or localised defects in the retinal nerve fibre layer. These three features will be discussed separately.

\section{Colour appreciation}

Colour appreciation at the optic disc is open to gross observer error. Firstly, diffuse illumination of the posterior fundus (achieved with a direct ophthalmoscope or colour photography), allows 'colour leak' from the peripapillary choroid to the adjacent optic disc, giving a falsely pink appearance to pale disc tissue (Gloster, 1971).

Illumination of the optic disc without the peripapillary choroid, by means of a narrow beam of light, allows more accurate colour appreciation by limiting colour leak (Gloster and Parry, 1974). The narrow light beam allows colour comparisons to be made between corresponding areas of the neuroretinal rim above and below the horizontal meridian of the optic disc, or nasal and temporal to the vertical meridian. By limiting these colour differences to 'pink' or 'pale', gross differences between similar areas (upper temporal sector of the neuroretinal rim and lower temporal sector, etc.) of one or both optic discs of one may be noted (Hitchings and Spaeth, 1976).

The second major source of observer error is the false appreciation of optic disc colour produced by alterations in the optical media of the eye. The light reflected from the eye is affected by the senile lens, which acting as a filter frequently imparts a pinkish hue to the optic disc (Snydacker, 1964; Kronfeldt, 1967). In contrast the optic disc in an aphakic eye seems paler than its fellow seen through a lens. Neither of these two factors was present to affect colour appreciation for the patients in this study.

Slit-lamp biomicroscopy showed diffuse pallor of the affected optic discs in the eyes presented in this paper. In contrast eyes with 'typical' chronic simple 

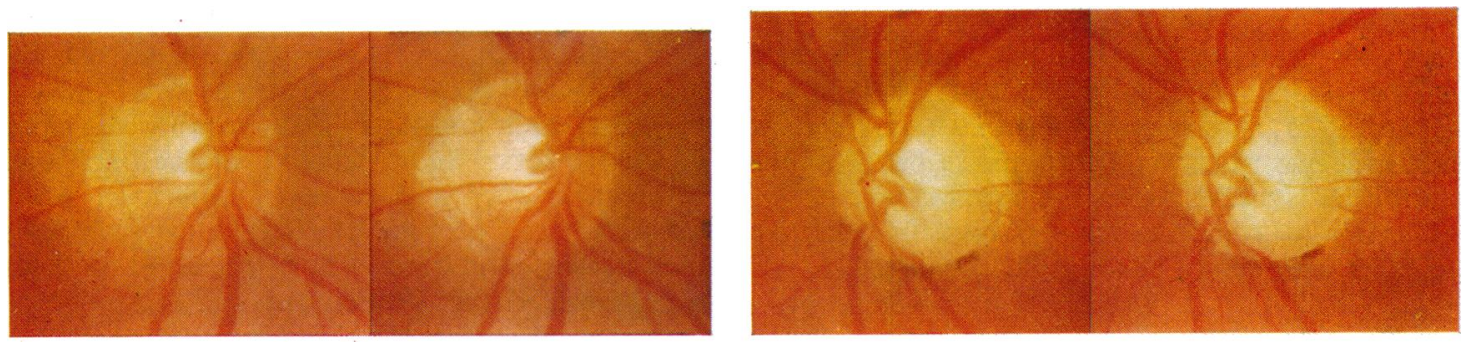

Fig. 1 Right and left optic disc of Patient 8. The right disc was considered normal, the left disc showed diffuse pallor of the neuroretinal rim and was considered abnormal
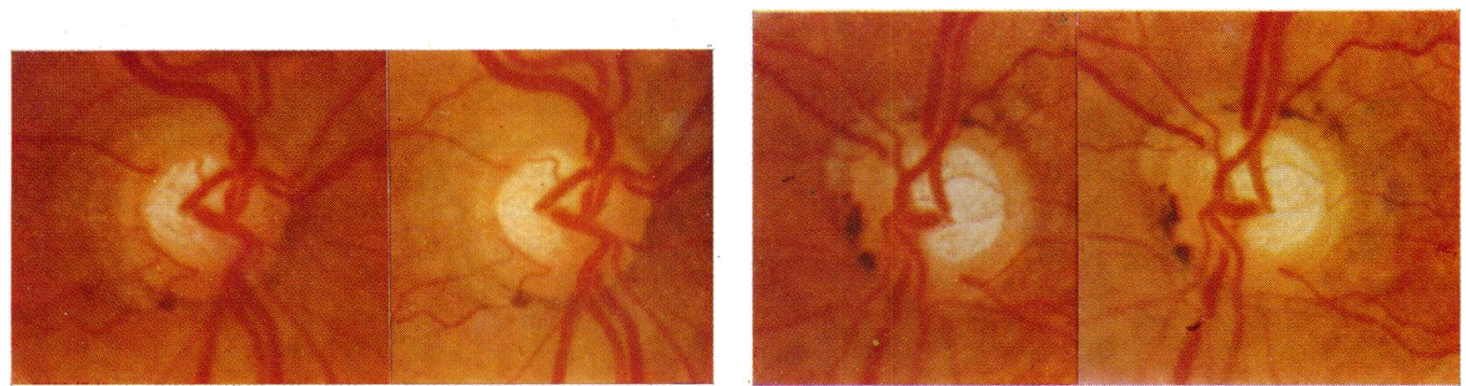

Fig. 2 Right and left disc of Patient 2. The right optic disc is pink in colour and considered normal; note the large $C / D$. The left optic disc shows uniform pallor of the neuroretinal rim, a larger C/D ratio with a circular orifice to the optic cup, and was considered abnormal

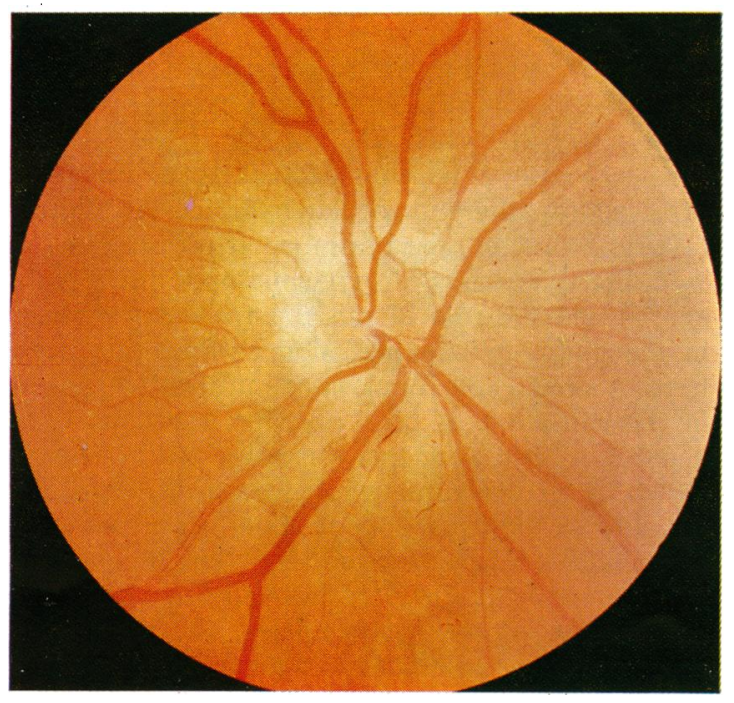

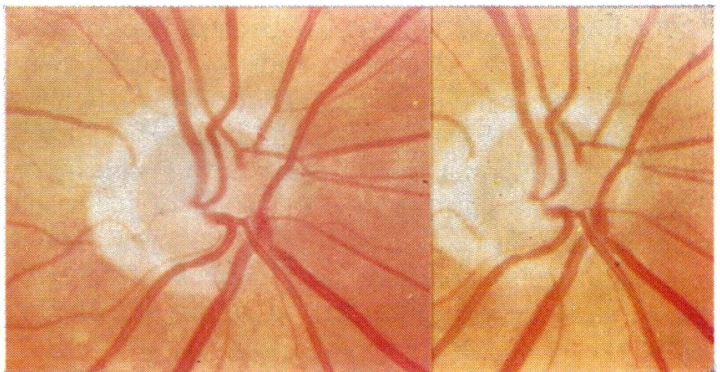

Fig. 4 Right eye of Patient 10, at presentation to the author. Note depressed optic cup and diffuse pallor of the neuroretinal rim

Fig. 3 Right eye of Patient 10 at the time of presentation with a 'typical' acute ischaemic optic neuropathy. Note swollen nerve head and haemorrhages

Note: 'Colour leak' (see text) from the peripapillary choroid has made the pallor, where present, less obvious. Intact nerve fibre bundle layers were visible on biomicroscopy in the right eye of Figs. 1 and 2. Figs 1, 2, and 4 are stereopairs and should be viewed through a plus sphere suitably decentred 
glaucoma have pallor of the neuroretinal rim receiving neurones from the defective visual field (Armaly, 1969; Douglas et al., 1974; Hoskins and Gelber, 1975; Hitchings and Spaeth, 1977). Schwartz (1973) suggested recently that diffuse pallor of the optic disc occurs only in terminal glaucoma, indicating neuronal loss from all parts of the retina together with loss of most of the visual field.

\section{Localised thinning of the neuroretinal rim}

Localised thinning of the neuroretinal rim has been shown to be a sign of 'typical' chronic simple glaucoma (Hitchings and Spaeth, 1976). Thinning is most easily identified by stereoscopic biomicroscopy, comparisons being made between the sector of rim in question and the corresponding sector in the other eye or the corresponding sector above or below the horizontal in the same eye. The 14 eyes with diffuse pallor did not show localised thinning of the neuroretinal rim despite field defects limited in some cases to one upper or lower half of the visual field. In those patients for whom 1 disc, being pink with a small optic cup, appeared normal comparison between the glaucomatous and normal eye showed the neuroretinal rim in the former to be uniformly thinner. As might be expected, cup-to-disc ratios tended to be considerably larger in the abnormal eye.

\section{Nerve fibre bundle defects}

Nerve fibre bundle defects have been shown to occur in patients with glaucoma and to coincide with defects in the visual field (Hoyt et al., 1973; Hitchings and Spaeth, 1977). Although many eyes with advanced glaucoma do not have any visible nerve fibre layer notwithstanding the state of the visual field (Hitchings and Spaeth, 1977), eyes having relatively well localised field defects frequently show 'gaps' or 'grooves' in the retinal nerve fibre layer.

None of the eyes with diffuse optic nerve pallor presented in this paper had visible retinal nerve fibres despite visual fields that ranged from 'normal' to an altitudinal field loss. In contrast all of the eyes with pink optic discs had an intact retinal nerve fibre layer. The optic discs with diffuse pallor may have suffered loss of sufficient neurones to abolish the reflexes arising from the inner retina, but, apparently, not enough to produce defects detectable by kinetic Goldmann field testing in each part of the visual field.

SIMILARITIES BETWEeN THE CASES PRESENTED AND 'TYPICAL' ISCHAEMIC OPTIC NEUROPATHY Case 1 was referred to the author $2 \frac{1}{2}$ years after bilateral ischaemic optic neuropathy following the later development of raised intraocular pressures. At that time the physical signs were the same as for the other cases presented.

Quigley and Anderson (1978) recently described in a large series the appearance of the optic disc before and after a documented attack of acute ischaemic optic neuropathy. They noted each optic disc developed diffuse pallor. Those optic discs which, before the attack, had small optic cups developed 'flat white discs', while in the much less common eyes in which the optic cup was large before the attack the appearance of the disc after the attack was that of a pale cupped disc-differing from 'typical' chronic simple glaucoma in that the orifice of the optic cup was circular rather than vertically oval. Quigley and Anderson's observation that the optic disc may appear glaucomatous in eyes with large optic cups before an acute ischaemic optic neuropathy agrees with the findings for the cases presented in this paper, where each of the 5 normal fellow eyes had quite large optic cups.

Reviewing the visual field defects in their series of cases of ischaemic optic neuropathy Quigley and Anderson (1978) found defects to exist predominantly either in the inferior half of the visual field or as a central scotoma, whereas in glaucoma the early field defects affect the superior half ot the visual field (Harrington, 1971). Our patients had field defects sited most frequently in the lower half of the visual field and/or a central scotoma.

\section{RELATIONSHIP BETWEEN ELEVATED INTRAOCULAR PRESSURE AND ISCHAEMIC OPTIC NEUROPATHY}

Previous reports have associated acute ischaemic optic neuropathy with ocular hypertension. Foulds (1969) on finding raised intraocular pressure in 7 of 24 consecutive cases of ischaemic optic neuropathy emphasised the role of raised intraocular pressure in reducing capillary perfusion at the optic nerve head. A similar role for elevated intraocular pressure in the causation of both anterior ischaemic optic neuropathy and glaucoma was suggested by Hayreh (1974). A relatively minor role for raised intraocular pressure in the causation of acute ischaemic optic neuropathy was suggested by the findings of Ellenberger et al. (1973), who found no difference between the intraocular pressure in 48 patients with acute optic neuropathy and an equal number of age and sex matched controls. Similarly, Eagling et al. (1974) noted raised intraocular pressure in only 1 of 40 cases with ischaemic optic neuropathy, while Quigley and Anderson (1978) detected raised intraocular pressure in only 5 of their 78 cases. No conclusion can be drawn from the cases presented in this paper because referral to the author depended 
on the association of raised intraocular pressure and glaucomatous cupping.

Although these more recent studies suggest a minor role for raised intraocular pressure in the production of ischaemic optic neuropathy, it is of importance as a condition relatively easy to treat. The apparently normal second eye of a patient whose first eye suffered an acute ischaemic optic neuropathy may run a greater risk of developing the same condition if the intraocular pressure is raised above normal. Even if such an eye shows no sign of damage from the raised pressure, prophylactic antiglaucoma therapy should be given.

\section{Conclusion}

This paper has presented a series of eyes with intraocular pressures greater than $21 \mathrm{mmHg}$, glaucomatous cupping, and in most instances visual field defects. Although by definition each eye suffered from chronic simple glaucoma, atypical features were present in every case. It is suggested that each eye had suffered an ischaemic optic neuropathy.

It is important to differentiate between acute ischaemic optic neuropathy and 'typical' chronic simple glaucoma. The former causes sudden visual loss in contrast to the gradual visual loss in the latter condition. Both conditions may be bilateral. Although raised intraocular pressure may only be a minor factor precipitating an acute ischaemic optic neuropathy, its discovery in the fellow eye of a patient who has suffered such an acute attack merits topical antiglaucoma treatment, even without evidence that the raised intraocular pressure has damaged the eye, in contrast to ocular hypertensive eyes with 'typical' chronic simple glaucoma in the other eye, when under similar circumstances it is not mandatory to begin prophylactic antiglaucoma treatment.

Optic nerve disease and visual loss in chronic simple glaucoma probably occurs as a result of several different mechanisms. Sudden field loss following an acute ischaemic optic neuropathy may be only one of them.

I thank Professor J. Gloster and Mr A. C. Bird for helpful discussion during the preparation of this manuscript, and Miss D. Martin for typing it.

\section{References}

Anderson, D. R. (1975). Pathogenesis of glaucomatous cupping: a new hypothesis. Symposium on Glaucoma. Transactions of the New Orleans Academy of Ophthalmology. Mosby: St. Louis.

Armaly, M. (1969). The correlation between appearance of the optic cup and visual function. Transactions of the
American Academy of Ophthalmology and Otolaryngology, 73, 898-913.

Douglas, G. R., Drance, S. M., and Schulzer, M. (1974). A correlation of field and disc changes in glaucoma. Canadian Journal of Ophthalmology, 9, 391-402.

Eagling, E. M., Saunders, M. D., and Miller, S. J. H. (1974). Ischaemic papillopathy. British Journal of Ophthalmology, 58, 990-1008.

Ellenburger, C., Keltner, J. L., and Burde, R. M. (1973). Acute optic neuropathy in older patients. Archives of Neurology, 28, 182-185.

Foulds, W. S. (1969). Visual disturbances in systemic disorders, otpic neuropathy and systemic disease. Transactions of the Ophthalmological Societies of the United Kingdom, 89, 125-146.

Gloster, J. (1971). Some recent work in glaucoma. Proceedings of the Royal Society of Medicine, 64, 938-952.

Gloster, J., and Parry, D. G. (1974). The use of photographs for measuring cupping in the optic disc. British Journal of Ophthalmology, 58, 850-862.

Harrington, D. O. (1971). The Visual Fields, 3rd edn., pp. 186. Mosby: St. Louis.

Hayreh, S. S. (1974). Pathogenesis of cupping of the optic disc in glaucoma. British Journal of Ophthalmology, 58, 863-876.

Hitchings, R. A., and Spaeth, G. L. (1976). The optic disc in glaucoma, I: Classification. British Journal of Ophthalmology, 60, 778-785.

Hitchings, R. A., and Spaeth, G. L. (1977). The optic disc in glaucoma, II: Correlation of the appearance of the optic disc with the visual field. British Journal of Ophthalmology, 61, 107-113.

Hoskins, H. D., and Gelber, E. C. (1975). Optic disc topography and visual field defects in patients with increased intraocular pressure. American Journal of Ophthalmology, 80, 284-292.

Hoyt, W. F., Frisen, L., and Newman, N. (1973). Fundoscopy of the nerve layer in glaucoma. Investigative Ophthalmology, $12,814-829$.

Kirsch, R. C., and Anderson, D. R. (1973). Identification of the glaucomatous disc. Transactions of the American Academy of Ophthalmology and Otolaryngology, 77, 143156.

Kronfeldt, P. C. (1967). The optic nerve. Symposium on glaucoma. Transactions of the New Orleans Academy of Ophthalmology, Chapter 3. Mosby: St. Louis.

Portnoy, G. L. (1973). Qualitative parameters of the normal optic nerve head. American Journal of Ophthalmology, 76, 655-659.

Portnoy, G. L. (1975). Photogrammatic analysis of volume asymmetry of the optic nerve cup in normal, hypertensive and glaucomatous eyes. American Journal of Ophthalmology, 80, 52-58.

Quigley, H. A., and Anderson, D. R. (1978). Cupping of the disc in ischaemic optic neuropathy. Transactions of the American Academy of Ophthalmology and Otolaryngology, 83, 755-762.

Schwartz, B. (1973). Cupping of the optic disc. Archives of Ophthalmology, 89, 272-276.

Snydacker, D. (1964). The normal optic disc. American Journal of Ophthalmology, 58, 958-963.

Tomlinson, A., and Phillips, C. I. (1974). Ovalness of the optic cup and disc in the normal eye. British Journal of Ophthalmology, 58, 543-549.

Weisman, R. L., Asseff, C. F., Phelps, C. D., Podos, S. M., and Becker, B. (1973). Vertical elongation of the optic cup in glaucoma. Transactions of the American Academy of Ophthalmology and Otolaryngology, 77, 157-163. 